\title{
Letter \\ Using surface molecule expression on lymphocytes to classify septic shock patients
}

\author{
Jorge Monserrat ${ }^{1}$, Raul de Pablo², Alfredo Prieto ${ }^{1}$, Eduardo Reyes ${ }^{1}$ and Melchor Álvarez-Mon ${ }^{1,3}$
}

\author{
${ }^{1}$ Laboratory of Immune System Diseases and Oncology, National Biotechnology Center-Department of Medicine (CNB-CSIC) Associated Unit, \\ University of Alcalá, Carretera Madrid-Barcelona, Km 33,600, Alcalá de Henares, 28871 Madrid, Spain \\ 2Intensive Care Unit, Hospital Universitario Príncipe de Asturias, Alcalá de Henares, 28871 Madrid, Spain \\ 3Immune System Diseases and Oncology Service, Hospital Universitario Príncipe de Asturias, Alcalá de Henares, 28871 Madrid, Spain
}

Corresponding author: Melchor Alvarez-Mon, jorge.monserrat@uah.es

Published: 25 June 2009

Critical Care 2009, 13:412 (doi:10.1186/cc7919)

This article is online at http://ccforum.com/content/13/3/412

(C) 2009 BioMed Central Ltd

See related commentary by McDunn and Hotchkiss, http://ccforum.com/content/13/2/127, and related research by Monserrat et al., http://ccforum.com/content/13/1/R26

In agreement with McDunn and Hotchkiss [1], we hypothesized that the simultaneous analysis of different immune system cell subsets would improve the prediction of outcome in septic shock patients. Abnormal redistribution of $\mathrm{T}$ lymphocyte, NK-lymphocyte and B-lymphocyte subsets has been found to be involved in the pathogenesis of other diseases, but the evidence reported in critical illness is less compelling [2]. In addition to the results described in our previous paper, and following a cytomic analysis [3], we have also studied the predicting value for outcome of combining different T-cell, B-cell and NK-cell markers in the 52 septic shock patients reported in our article [4].

Receiver operating characteristic curves were built for each phenotypic variable. The sensitivity and specificity of each variable to predict the real outcome was thus obtained [5]. The variables with higher sensitivity values were selected and combined to create multiple variable combinations or masks. The mask with the highest sensitivity and specificity was selected to predict the outcome of these patients.

According to this methodology we have found a set of five immunophenotypic variables $\left(\mathrm{CD}^{+} \mathrm{CD}^{+} \mathrm{CD}^{2} 8^{+}, \mathrm{CD}^{+-}\right.$

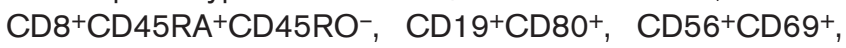
$\left.\mathrm{CD}^{+} \mathrm{CD} 11 \mathrm{~A} \mathrm{br}^{+} \mathrm{CD} 11 \mathrm{~B}^{+}\right)$and their cutoff values $(163,114$, $67,114,250$ lymphocytes/ $\mu$ l, respectively) that are able to improve the prediction for outcome in septic shock patients to a sensitivity of $94 \%$ and a specificity of $100 \%$. We therefore conclude that the immunophenotypic study of peripheral blood mononuclear cells is useful to predict the outcome of septic shock patients.

\section{Competing interests}

The authors declare that they have no competing interests.

\section{Acknowledgements}

The authors would like to thank all of the medical doctors and nurses of the intensive care unit of the Hospital Universitario Principe de Asturias for their careful and generous collaboration while doing this work. The present study was supported by grants S-BIO-0189/2006 MITIC/TIMEDIC from Comunidad de Madrid and 98/1431 Fondo de Investigaciones Sanitarias, CIBERehd, and by a research prize awarded by the Fundación Lilly.

\section{References}

1. McDunn JE, Hotchkiss RS: Leukocyte phenotyping to stratify septic shock patients. Crit Care 2009, 13:127.

2. Annane D, Bellissant E, Cavaillon JM: Septic shock. Lancet 2005, 365:63-78.

3. Valet G: Predictive medicine by cytomics: potential and challenges. J Biol Regul Homeost Agents 2002, 16:164-167.

4. Monserrat J, de Pablo R, Reyes E, Diaz D, Barcenilla H, Zapata MR, De la Hera A, Prieto A, Álvarez-Mon M: Clinical relevance of the severe abnormalities of the T cell compartment in septic shock patients. Crit Care 2009, 13:R26.

5. McNeil BJ, Hanley JA: Statistical approaches to the analysis of receiver operating characteristic (ROC) curves. Med Decis Making 1984, 4:137-150. 